\title{
Den svenska modellen för nanoteknik - mer effektiv än reflexiv?
}

\author{
Hans Fogelberg
}

Syftet med artikeln är att diskutera organiseringen av svensk nanoteknik och varför denna skiljer sigfrån de länder inom vilka det sker en mer sammanhållen aktörsmobilisering kring nanoteknik, och där tillväxtfokus i högre grad än i Sverige integreras med fokus på miljö och samhällsmässiga aspekter. Utvecklingen av svensk nanoteknik visar att vetenskaplig effektivitet inte nödvändigtvis betyder att frågor om innovation eller effekter av denna innovation också hanteras effektivt. Stora vetenskapsprogram drivs utan samordnande hantering av nanoteknik som innovationsobjekt. Forskning om miljö och samhälleliga aspekter sker i liten skala och utan tydlig koppling till nanoteknikens innovationssystem. Förklaringar söks i den svenska modellens implikation för FoU $i$ allmänhet och nanoteknik i synnerhet. Modellen är centrerad kring storindustrins behov och har sitt fokus på expertis. Sammantaget har Sverige haft svårt både att hantera nanoteknik som utvecklingsprojekt och att bredda diskussionen kring nanoteknik som samhällsprojekt.

Nyckelord: nanoteknik, svenska modellen, reflexivitet, innovation

\section{Inledning ${ }^{1}$}

Schummer (2007) lyfter fram tre vanligt förekommande definitioner av «nanoteknik»: skala, vision respektive praktik (författarens översättning). Nanoteknik som skalnivå utgår från den dimension, inom vilken, nya material kan designas och ges radikalt nya egenskaper och tillämpningar. Nanoteknik som vision definierar tekniken utifrån önskade framtider och övergripande samhälleliga mål. Nanoteknik som praktik definieras som den faktiska organiseringen av förhållandevis disparata forsknings- och teknikområden inom ramen för större satsningar, $\mathrm{t}$ ex i form av nanoprogram. 
Schummer använder den senare definitionen för att utveckla ett resonemang kring etiska frågor i förhållande till teknikens kontext. Denna artikel knyter också an till den sistnämnda definitionen, men fokuserar istället på graden av reflexivitet genom att studera organisering av nanoteknik som (kontextuellt) innovationsprojekt.

Med nanoteknik avses därmed något mer än bara den interna inomvetenskapliga verksamheten och det forskare producerar i laboratoriet i form av nya material och ytterst små artefakter med radikalt ny funktionalitet. Med «nanoteknik» avses också forskningens olika kontexter (se t ex Fogelberg \& Glimell 2003), eller hur olika delar av en vidare social, historisk och materiell kontext tillsammans bildar ett system för innovation. Nationella initiativ för nanoteknik ses i detta sammanhang som «organisatör» av innovationssystem. Ett kontextuellt angreppssätt är synonymt med hur teknikhistoriker inom teknikstudier (Hughes 1986; 1987), tekniksociologer inom teknik- och vetenskapsstudier (Latour 1996; Callon \& Law 1989) samt evolutionär ekonomi inom innovationsstudier (Cowan 1990; Carlsson 1997), närmar sig andra teknologiområden (för en beskrivning av skillnaden mellan internalism vs. kontextualism inom teknikstudier, se Staudenmaier 1985; Smith \& Reber 1989). En vanlig invändning är att kontext saknas och att nanoteknikens «utsida» enbart finns i dokument och som "projekt», men ej i verkligheten. Analytikerns arbetsinsats blir förstås större när det gäller att påvisa kopplingar mellan in- och utsida där den allmänna meningen är att sådana kopplingar saknas eller ej ännu hunnit etableras. Emellertid ligger det enligt Latour (1993) i det moderna samhällets logik att underskatta omfattningen av vetenskapens täta band till samhället. Nanovetenskaplig forskning kan betraktas som toppen av det teknovetenskapliga isberg där den kontextuella basen är stor, men dolda under ytan (jfr Latour 1987: 145-176). Med ett kontextuellt synsätt kan vi t ex uppskatta hur formulering, aktörsmobilisering och organisering av nanoteknik som explicit teknikprojekt pågått under längre tid, exempelvis i Sverige under närmare 25 års tid (Fogelberg \& Sanden 2008).

Artikeln baseras på en enkel tanke om att reflexiva innovationssystem är att föredra framför system vilka karaktäriseras av mer slutna och linjära processer. Istället för att dra en skarp linje mellan reflexiv respektive ickereflexiv innovation bör man tala om en gradskillnad. Vad som å ena sidan på ett slags teoretiskt plan kan förväntas av en viss typ av reflexiv funktion, respektive vad som å andra sidan visat sig vara ett historiskt utfall av tidigare processer. Det är också på detta sätt artikeln relaterar till tidigare och existerande former och försök att skapa reflexiva innovationsprocesser. Den beskrivning Fisher et al. (2006) ger kan användas för att belysa detta. Teknikvärdering (TA) bygger på en tanke om att man, någorlunda säkert, kan fastställa olika tekniska lösningars egenskaper och effekter, och låta detta utgöra bas för beslut «upstream» och reglering «downstream». Inom det 
vetenskapliga området skapades i USA utifrån en liknande tanke ett ELSIprogram (ethical, legal and social implications) inom ramen för Human Genome Project. Emellertid kom det historiska resultatet av dessa organiseringar att kritiseras för att misslyckats med att påverka processerna, eller $\mathrm{t} o \mathrm{~m}$ ha fungerat som legitimering av linjär process snarare än bidragit till ökad reflexivitet (Fisher 2005). Flera nya formuleringar utvecklades som reaktion på denna och liknande kritik. Konstruktiv teknikvärdering, CTA, kan ses som ett försök att förädla teknikvärderingsprocessen. Genom att öka bredden av kriterier och signaler i tidiga teknikutvecklingsskeden är tanken att innovationsprocesserna förmår integrera samhälleliga aspekter på ett bättre sätt (Schot \& Rip 1997). Ett program och en faktisk organisering av konstruktiv teknikvärdering av nanoteknikutveckling ingår numera i det holländska nanoprogrammet NanoNed (Rip 2005). Guston och Sarewitz (2002) bygger i sin tur vidare på konstruktiv TA och föreslår vad de kallar realtids-TA (real-time TA), vilken kontinuerligt analyserar och kommunicerar med innovationsprocessen. Både konstruktiv TA och realtids-TA är formuleringar vilka tar avstamp i denna kritik av resultaten från tidigare erfarenheter från TA- och ELSI-liknande program. ELSA (ethical, legal, and societal aspects) används ibland på liknande sätt, för att lyfta fram en mer reflexiv roll. Ovanstående skifte kan ses som del av en mer övergripande och allmän diskussion om reflexiva processer i kunskapssamhället (Felt \& Wynne 2007).

Det underliggande kunskapsintresset är att försöka förstå på vad sätt utvecklingen av nanoteknik är eller kan bli «systemiskt reflexiv». Med reflexiv menas här en systemfunktion och en förmåga hos de nya innovationssystem som byggs kring nanoteknik att identifiera behov och undvika risker. I grunden handlar detta om att förutse och interagera med en rad, inom teknikstudiet, väl kända fenomen. Utifrån en förhållandevis öppen situation sker tidiga teknikval via sociala processer (Pinch \& Bijker 1984; Bijker 1995) och tekno-ekonomiska processer (Cowan 1990). Resultatet är etableringen av en dominerande lösning och en spårberoende teknikutveckling vilket leder till en slags inlåsningseffekt (Cowan 1990) eller till och med irreversibla fenomen (Van Merkerk \& Van Lente 2005). Såtillvida att det byggs upp större socio-tekniska system kring en teknologi leder dessa med tiden till olika slag av (systemisk) tröghet (Hughes 1987), vilket också försvårar en förändringsprocess.

Dessa teknikutvecklingsfenomen kan relateras till Ulrich Becks tanke om att moderna teknikintensiva samhällen behöver utvecklas i mer öppna och reflexiva system (Beck 1992). Lash (2007) pekar på att Becks modell baseras på reflexivitet i ett icke-linjärt system och att detta på ett intressant sätt binder samman Beck med både Latours (1996) virvelvindsmodell för innovation samt Luhmanns (2005) modell om riskhantering i självorganiserande system. Ett (icke-linjärt) reflexivt system (eller aktörsnätverk) är i 
grunden instabilt och i ständig förändring. De reflexiva processerna konstituerar systemet snarare än att bara vara små justeringar till en i övrigt linjär utveckling. Det innebär att reflexiva innovationssystem processar information och påverkas av många olika och tidiga signaler (tidig t ex i bemärkelsen osäker kunskap). Detta förhållningssätt till risk skiljer ut både bioteknik och nanoteknik från traditionell riskanalys, där utfallen förutsätts vara någorlunda kända och beräkningsbara (Hansson 2005). Det binder också samman reflexivitet och innovation på ett intressant sätt. För en generisk teknik - som nanoteknik - med många möjliga framtider, blir vikten av aktiva val kring önskvärda framtider uppenbar.

I fokus för artikeln står den svenska evolutionära utvecklingen av nanoteknik, vilken av olika skäl är forskningsmässigt välutvecklad och effektiv, utan att för den skull lett till skapandet av funktioner i innovationssystemet, vilka fungerar som centrum för reflektion och diskussion kring innovation och risk. Länder vilka mer aktivt konstruerat fokus på och utveckling av nanoteknik har i flera fall - med USA som modell - konstruerat fokus även på samhälleliga och miljömässiga aspekter av nanoteknikutveckling. Detta gäller även länder vilka ännu inte lanserat egna nationella nanoinitiativ, men vilka likväl hanterat frågan om ansvarsfull nanoinnovation på nationell nivå. I förhållande till denna iakttagelse ställs frågan vad det betyder för det svenska systemet för nanoinnovation och hanteringen av nanorisk att det saknas en öppen och bred samhällelig diskussion om nanoteknik i Sverige.

\section{Den internationella organiseringen av ny teknikbas}

I en ny handbok inom teknik- och vetenskapsstudier ägnas nanoteknik stort utrymme, där Barben et al. (2008) pekar på en rad intressanta saker. Dels att flera högteknologiska länder världen över sedan slutet av 1990-talet arbetar med att organisera forskning och utveckling av nanoteknik som nationellt projekt. Dels att dessa satsningar omfattar policy kring utvecklingens etiska, legala och samhälleliga aspekter på ett sätt som skiljer sig från liknande och tidigare erfarenheter inom bioteknologiområdet, genom att reflexiva processer institutionaliseras på ett tydligare sätt.

I länder med forskningsintensivt näringsliv handlar det i flera fall om en uppskalning och mer sammanhållen organisering av redan existerande processer. Två närliggande exempel är Tyskland och Storbritannien.

Tyskland genomförde flera studier och teknikvärderingsaktviteter av nanoteknik under 1990-talet (Bachmann 1998), och organiserade från 1998 flera nätverk och kompetenscentrum för nanoteknik, vilket också inkluderade finansiering av olika samarbetsprojekt inom nanoområdet. Dessa aktiviteter omformades nyligen till ett större och explicit nationellt initiativ för nanoteknik, vilket förutom att fokusera på teknik och marknad även 
omfattar det parallella studiet av sociala och miljömässiga konsekvenser (BMBF 2004; Rieke \& Bachmann 2004).

Storbritannien var också tidigt ute med att formulera nanoteknik som nationellt projekt och drev flera sådana program redan år 1988 (Hirst 1996). Emellertid utvecklades inte dessa verksamheter till ett större sammanhållet nationellt program för nanoteknik. Den s.k. Taylorrapporten från 2002 lägger grunden för en sådan nationell samordning, mot bakgrund av att innovationssystemet för nanoteknik bedömdes vara alltför distribuerat och baserat på informella nätverk (UK Advisory Group on Nanotechnology Aplications 2002). Avsaknaden av ett nationellt program betyder inte att det saknas ett nationellt innovationssystem för nanoteknik, eller att nano saknar nationell hantering på en övergripande nivå. Systemfunktioner för tillväxt har skapats. Redan existerande fokus på innovation och tillväxt förstärktes via skapandet av Technology Strategy Board, vilken f.n. implementerar ett större nanoprogram, samt via etableringen av Nanotechnology Knowledge Transfer Network, med syfte att driva på kommersialiseringen av nanoteknik. Storbritannien rapporteras ha fler än 600 nanoteknikföretag (UK Trade \& Investment 2008). Även en systemfunktion för risk och dialog med det bredare samhället har skapats. En större teknikutvärdering genomfördes med uppdraget att utreda nanoteknik med avseende på etik, sociala frågor, hälsa, miljö samt risk (Royal Society and Royal Academy of Engineering 2004). Nanoteknikdebatten gavs publik exponering även genom andra studier (t ex Economic and Social Research Council 2004), via social interaktion (t ex Demosprojektet, se Kearnes et al. 2006) samt via framväxten av en medial exponering och medial ram för nanofrågor (Anderson et al. 2005). Riskfrågorna kanaliserades och hanterades via Nanotechnology Research Coordination Group (Defra 2007), och frågor kring "public concerns» och «responsible innovation» integrerades i ett särskilt program (HM Government 2005a). Ett av delområdena var «upstream public engagement», där redan existerande projekt (Nanodialogue, Small Talk, Nanotechnologies Engagement Group) integrerades med andra satsningar och en plan för ytterligare framtida projekt (HM Government 2005b). Men integrationen av reflexiva processer är inte enkel. Doubleday (2007) pekar i sin analys av «upstream engagement» på att analysen och reflektionen kring samhälleliga frågor och återkopplingen av dessa till nanoforskning på ett plan är effektiv och fungerar väl, men finner också att hela frågan får en olycklig inramning via aktörernas föråldrade föreställningar vad gäller både «science» och «public».

Ovanstående beskrivning exemplifierar att det sker en organisering av innovation, riskforskning och reflektion, och att denna organisering på ett tydligt sätt motiveras av en ambition att på nationell nivå och tillsammans med aktörer skapa och forma innovationssystemets framväxt. I kontrast till i Tyskland sker detta fn utan ett explicit nationellt nanoinitiativ. 
I Sveriges omedelbara närhet finns länder vilka också har lyft frågan på ett tydligt sätt. Finland har t ex drivit explicita nanoprogram sedan 1997 (Tekes 2000; Tekes 2005). Satsningarna är vetenskaps- och tillväxtorienterade men innehåller ingen tydlig eller stark integrerad satsning på samhälle och miljö. Den sociala dimensionen är istället implicit och uttrycks via tillväxtmål (Langlais et al. 2004: 27). Danmark genomförde under 2004 en större teknikvärderingsprocess kring nanoteknik, vilket resulterade i en plan och förslag till en kommande nationell satsning där dels medelsnivån ökas markant och där vetenskap, innovation och riskhantering integreras $\mathrm{i}$ högre grad än tidigare (Videnskabsministeriet 2004). En aktuell innovationsstudie (Andersen \& Rasmussen 2006) pekar på att viktiga delar i ett FoU-system för nanoteknik etablerades redan för 10-15 år sedan. Under de senare åren sker en tydlig mobilisering och kraftsamling kring dessa. Ett regionalt viktigt centra, iNANO, etablerades vid Aalborgs Universitet år 2002. Tillsammans med etableringen av Nano DTU och skapandet av nytt renrum år 2004 vid Danmarks Tekniska Universitet, innebar detta en ytterligare aktörsmobilisering och intensifiering av redan existerande verksamheter kring nanovetenskap och nanoteknik. Det kanske mest tydliga och industriellt inbäddade innovationsspåret centreras kring nanokatalys och företaget Haldor Topsøe. Studien och Risølaboratoriets engagemang kan i sig ses som del av analys och återkoppling till det danska framväxande innovationssystemet för nanoteknik. Norge presenterade år 2006 en ambitiös plan för nanoteknik med syfte att expandera det tidigare nanoprogrammet NANOMAT. Planen placerar tidigare teknikprogram i ett nytt organisatoriskt sammanhang (Norges forskningsråd 2006) och inkluderar även etiska, juridiska och samhällsmässiga aspekter av nanoteknik, vilket utreddes separat (Norges forskningsråd 2005). I period två av NANOMAT definieras miljö och samhälleliga aspekter som särskilt kompetensområde (Norges forskningsråd 2007). Satsningen är innovationspolitiskt intressant mot bakgrund av att man delvis saknar en forskningsintensiv storindustri och därmed den historiska kontext kring vilken mobiliseringar centreras i flera andra länder.

Ovanstående exempel på nationella aktörsmobiliseringar och i förekommande fall, explicita nationella nanoprogram, konstrueras som tvärvetenskapliga forskningsprogram med i huvudsak natur- och teknikvetenskapliga fokus. De utmärker sig genom sin redan stora omfattning, eller, i förekommande fall, förslag till kommande program och ökad resurstilldelning. De utmärker också på det sätt att grundforskningen och teknikutvecklingen i flera fall kombineras och integreras med forskning om utvecklingens potentiella effekter.

Den sistnämnda formen av effektforskningen benämns ibland ELSA (Ethical, legal, societal aspects). Den roll ELSA ges i förhållande till nanoteknik är intressant. Samhällsvetare och humanister brukar normalt inte 
bjudas in i till de sammanhang där ny teknik formuleras och skapas. Det är en utmaning för samhällsvetenskaplig forskning, vilken inom ramen för tidigare processer tagit tekniken för given, snarare än deltagit i dess utformning (Macnaghten et al. 2005). Utgångspunkten i detta papper är att reflexiva innovationssystem är bättre än linjära dito. Även om ELSA kan leda till reflexiva processer på innovationssystemnivå så sker inte detta per automatik. Nanoteknikens policyaktörer kan fortfarande söka använda ELSA-forskning som instrument för legitimering av redan existerande planer snarare än som medel för förändring. Ett möjligt exempel på detta är det stora intresset policysystemet visar för allmänhetens uppfattningar och kunskaper om nanoteknik, vilket ges forskningsmedel inom ramen för ELSA-satsningar i t ex USA. I sig är denna mediaforskning intressant (se exempelvis: Stephens 2005; Lewenstein 2005; Bainbridge 2002; Macoubrie \& Cobb 2004). En instrumentell inramning skulle vara att använda forskningen som bas för information och kommunikation om nanoteknik med syfte att öka allmänhetens acceptans för den planerade utvecklingen, vilket påpekas av Ebbesen (2008). Emellertid finns inte heller någon automatik på detta plan. För en allmänhet som i de allra flesta fall har mycket små kunskaper om nanoteknik så leder inte automatiskt större kunskaper om nanoteknik till högre acceptans för utveckling och implementering (Kahan et al. 2006). Innovationssystemets olika aktörer är inbegripna i en kamp om definitioner och kontroll, det undgår inte ELSA. Däremot är det en förutsättning för en reflexiv process att forskare och en vidare grupp aktörer ges utrymme att delta överhuvud taget, och där spelar ELSA eller liknande satsningar en viktig roll.

\section{Den svenska modellens avtryck i FoU-systemet}

Man brukar tala om en specifikt svensk samarbetsmodell för att bygga samhälle och ekonomisk välfärd. Denna samhällsmodell utvecklade ett starkt korporatistiskt drag där arbetsmarknadens parter och andra organiserade partsintressen inkorporerades och tilläts delta i politiska processer (Rothstein 1992). Förutsättningen var att aktörer inom ramen för ett visst samarbete antas bidra till det allmännas bästa snarare än enbart tillgodose sina egna intressen (Öberg 1997). En liknande samarbetsmodell kan sägas ha existerat mellan å ena sidan staten och statliga FoU-aktörer och å den andra sidan svenska industriföretag. Under 1900-talet skapades intima samarbeten kring utveckling och införande av ny teknik och tekniska system där en förhållandevis liten grupp individer formade planer för kommande stora tekniska system. Samarbetet var på många sätt effektivt. Det skapades offentligt-privata institutionella «utvecklingspar» vilka fungerade som mekanismer för teknisk modernisering (Fridlund 1999). Det gemensamma 
intresset var att kombinera ökad internationell konkurrenskraft hos industrin med uppbyggnaden av en svensk materiell välfärd respektive militär alliansfrihet. Samverkansmodellen byggde på att staten agerade beställare och att olika aktörer agerade leverantör. Exempel är Vattenfall, Asea, Televerket, Ericsson, Försvaret, Saab, Scania, Volvo, Bofors, $m$ fl (NUTEK 2000: 81). Samarbetet var betydligt mer intimt än vad språkbruket «beställare/ leverantör» antyder. Fridlund (1999) ger en rad exempel på utvecklingspar: LM Ericsson/Televerket (telefoni och senare spin-off till mobiltelefoni), ASEA/Vattenfall (elsystem respektive kärnkraft), Bofors/FMV (försvarsmateriel), Saab/FMV (flyg), Scania/Postverket (bussar), Kockums/FMV (ubåtar) (se även Kaijser 1994; Weinberger 1996). Andra företag som bör nämnas i detta sammanhang är Astra och Electrolux. Särskilt viktiga för ekonomin under 1990-talet var Ericsson och Astra (Henrekson \& Rosenberg 2001: 209). Flera av företagen ovan anses än idag, trots globalisering och förändrade ägarförhållanden (inklusive namnbyten), vara centrala aktörer i det svenska systemet för innovation och välfärd.

Företag som växte upp i denna svenska (innovations)modell hade också en delvis annan kontext, vilken kom att förstärka samma tendens till täta samarbeten och kom att påverka FoU-systemets utformning och storlek. Svensk alliansfrihet innebar ett behov av en nationell bas för avancerad kunskap inom framför allt materialvetenskaperna, mikroelektroniken och avancerad systemingenjörsvetenskap. Modellens grundtanke om att kombinera (civila och militära) offentliga målbilder med ökad internationell konkurrenskraft för svensk storindustri gav forskningspolitiskt avtryck.

Huvudsyftet med organiseringen av svensk teknisk forskning har sedan dess i allt väsentligt handlat om att understödja svenska storföretag med både allmänkompetens och spetskompetens. Det utvecklades med tiden en specifikt svensk innovationsmodell och «samhälleligt forskningskontrakt» vilken vilade på en tudelning mellan å ena sidan forskning (universitetens roll) och å den andra sidan avancerad teknisk utveckling och innovation (storföretagens roll) (Sörlin 2005). Även om försök fanns att skapa nya broar mellan den akademiska och kommersiella världen, bl a via stiftelser för strategisk forskning, så kvarstår i många stycken denna tudelning (Sörlin 2005). Traditionella former av intermediära organisationer, som t ex forskningsinstitut, har spelat en ovanligt liten roll i det svenska systemet (Benner \& Sandström 2000: 294). Detta skiljer sig från vad som anses vara ett typiskt mönster för organiseringen av tekniköverföring i andra industrinationer (Granberg \& Jacobsson 2006: 331). Sverige presenteras i detta avseende som en anomali. På grund av ett specifikt svenskt «forskningskontrakt» mellan stat och ett litet antal storföretag ansågs det inte behövas en stor svensk institutsektor (Sörlin 2005: 32-33). Offentligt finansierad forskning har därför sedan 1950-talet inriktats mot universitetssystemet snarare än en institutsektor (Edqvist 2003). Emellertid betyder inte detta att 
det saknats intermediära mekanismer, vilket flera av ovanstående studier också pekar på. När det gäller åtminstone forskningsnära samarbeten mellan akademi och industri är det istället verksamheter förlagda till universitet, såsom konsortieprogram och på senare tid program för kompetenscentra (jfr engineering research centres-ERCs) och storsatsningar på s.k. excellenta forskningsmiljöer (jfr centres of excellence) som spelar liknande roller som de roller de forskningsnära instituten spelar i andra länder.

Det var också inom en för det svenska samhället anonym men historiskt viktig satsning på materialkonsortier med början under 1990-talet som den materiella och organisatoriska grunden lades för svensk nanoteknik (se mer om «mikronik» och framväxten av svensk nano i Fogelberg \& Sanden 2008). Storföretag och högteknologiska företag var närvarande i materialkonsortiernas första fas, medan den involveringen minskade successivt $i$ den andra fasen och tredje fasen. Istället för en mobilisering med avseende på nanoteknik och nano-innovation stärktes istället den nanovetenskapliga forskningen, vilken kom att bli en angelägenhet för stora delar av ett starkt distribuerat svenskt forskningslandskap. I och med att expansionen skedde med fokus på vetenskap och med relativt få industrikontakter, förblev nanoteknik ett objekt och en angelägenhet för en snäv krets. Mindre försök gjordes att lyfta frågan om en bred svensk mobilisering, men det var på det hela taget en relativt låg aktivitet med avseende på att göra nanoteknik till en nationell angelägenhet.

Svensk expertis avvaktade också i det längsta med att anamma begreppet nanoteknik, även om det redan stod klart bland de närmast berörda nanoforskarna och policyaktörerna att det Sverige kallade materialvetenskapliga konsortier eller materialforskning, kallades nanoteknik i övriga världen. En möjlig förklaring är att svenska nanoforskare tenderar att förhålla sig till begreppet nanoteknik på två olika sätt. Det ena är att betrakta det som ett snävt vetenskapligt begrepp där nanoteknik är vad nanoforskare kan och gör i laboratoriet. Den här definitionen ligger nära kunskapen om fenomenen och kompetensen att fabricera nanoobjekt och hantera de vetenskapliga instrumenten. Expert på nanoteknik är den som förstår funktionen och kan bygga nanomaterial som fungerar. Riskexpert är den som kan skilja farlig från harmlös nanopartikel, och förstå nanotoxikologiska implikationer. Naturligtvis är då nanoforskarna de enda legitima experterna på nanoteknik. Det andra förhållningssättet till nanoteknik som begrepp är att se det som ett i huvudsak utomvetenskapligt policybegrepp och politiskt fenomen, eller helt enkelt en forskningsfinansiell «uppfinning». För forskaren blir då nanoteknik en term som politiker och policyaktörer använder i sin värld, men som är alltför oprecis för vara användbar i den värld forskaren lever i. Båda versionerna av begreppet nanoteknik har det gemensamt att de upprätthåller en gräns mellan vetenskapens in- och utsida. Men skapandet av nanoteknik som nationellt «objekt» kräver en 
hopkoppling mellan in- och utsida på ett sådant sätt att det skapas förutsättningar för en vidare definition av nanoteknik.

I flera andra länder skedde sådan sammankoppling mellan in- och utsida genom en kontextualisering av nanotekniken. Den processen drevs eller understöddes aktivt av nanoexpertis. Svensk nanoexpertis avstod från att lägga stor energi på en politisering, eller mer rättvisande, de saknade både tradition och plattform för att driva en sådan process. Den svenska modellen och samarbetsandan mellan starka intressen fungerade dåligt för en mobilisering av nanoteknik i en situation där industriföretag visade sig vara avvaktande eller skeptiska till nanoteknik. En för nanoområdet tidig studie av samband mellan vetenskapliga publiceringar och patent inom nanoteknikområdet påvisar att Norge och Finland har en förhållandevis hög andel patent $\mathrm{i}$ förhållande till antalet vetenskapliga publiceringar (Meyer \& Persson 1998). För Sverige gäller närmast det omvända, den vetenskapliga aktiviteten är hög medan avtrycken i patent är få. Svenska storföretag har marginell aktivitet inom området nanopatent och patentaktivitet är koncentrerad till tre företag, vilka tillsammans står för $43 \%$ av alla nanopatent i Sverige under åren 1994 till 2004 (Meyer 2005). Det har varit svårt för företagen att se mer exakt hur nanotekniken ökar företagets konkurrenskraft. Konsekvensen för politiska aktörer är att de har svårt att mobilisera för nanoteknik utan industrins aktiva medverkan. Denna låsning följer av den svenska FoU-modellens tradition och logik.

Resultaten och den vidare implikationen av den svenska styrnings- och teknikutvecklingstradition är flera. Dels är det inom en ofta snäv krets av representanter för starka intressen som viktiga framtidsfrågor avhandlas. Dels sker detta på arenor och via diskurser vilka inte alltid är så synliga för det övriga samhället. Dels är det idag svårt att sjösätta större satsningar om inte redan existerande industriintressen har samsyn om vikten av mobilisering och samarbete inom just detta område. Det som skedde i tidigare skeden, kring nya teknologier, var att starka övergripande offentliga och privata mål kunde kombineras och ges konkret materiell och social organisering. Idag är detta betydligt svårare.

\section{Modellens implikation för svensk nanoteknik}

\section{Den forsknings- och innovationspolitiska arenan}

Ungefär samtidigt som nanoteknik blommade upp internationellt som det riktigt stora forsknings- och innovationspolitiska objektet för högteknologiska nationers framtida konkurrenskraft så genomförde Sverige en stor dialogprocess där intressen från industrin samlades inom ramen för Teknisk Framsyn. Framsynsprocessen, som genomfördes år 2000 och 
följdes av en ganska omfattande uppdatering år 2004, drevs gemensamt av fyra tunga svenska organisationer: Kungl. Ingenjörsvetenskapsakademien, Närings- och teknikutvecklingsverket, Stiftelsen för Strategisk Forskning, samt Sveriges Industriförbund. I totalt 9 rapporter från år 2000 förekommer nanoteknik förutom i syntesrapporten (Teknisk Framsyn 2000a) i tre delrapporter: Produktionssystem (Teknisk Framsyn 2000b), Informationsoch kommunikationssystem (Teknisk Framsyn 2000c) samt Material och materialflöden i samhället (Teknisk Framsyn 2000d). De motsvarande rapporterna från uppdateringen år 2004 (Teknisk Framsyn 2004a; 2004b; 2004c; 2004d) har analyserats och jämförts med de ursprungliga rapporterna. Båda framsynsprocesserna visade sig ha svårt att kontextualisera och konkretisera nanoteknik med avseende på svensk innovationspolitik och industriell utveckling. Industriföretagen visade inte vid denna tidpunkt och ej heller senare något särskilt brinnande intresse för nanoteknikens utveckling. Det innebär att vid tidpunkten för framsynsprocessen var det bland deltagarna i praktiken bara Stiftelsen för Strategisk Forskning som var en tydlig proaktiv aktör för nanoteknik, och då främst genom sin roll som finansiär av vad som i praktiken handlade mest om nanovetenskaplig grundforskning (snarare än nanoteknisk utveckling). Det saknades alltså en aktör som hade både intresse och muskler att driva nanoteknik som innovationsobjekt och nationellt «projekt».

Ett bredare skikt av svenska aktörer började dock uppmärksamma omvärldens formuleringar av nanoteknik som just lämpligt för ett nationella åtagande. Industrimannen Carl Bennet hade av andra skäl än nanoteknik bildat gruppen «framtid för svensk industri» bestående av nyckelpersoner på hög nivå inom industri, fack och kommun. År 2002 presenterade gruppen ett tidigt förslag till en nationell satsning för nanoteknologisk forskning och utveckling med fokus på industriella tillämpningar, med särskilt fokus på kommersialisering av en av de forskningsmiljörer som startade i materialkonsortierna (nanometerkonsortiet i Lund) (Framtid för svensk industri 2002).

Förslaget om ett svenskt nationellt initiativ för nanoteknik återkom sedan allt oftare, t ex i den analys Svenska Institutet för Tillväxtpolitiska Studier gör av NNI-modellens ursprungsland USA (Ahlgren \& Franchi 2005) samt i den analys Verket för Innovationssystem genomför av nanoteknik (Perez \& Sandgren 2007). Den senare rapporten kom att bli en del av Ingenjörsvetenskapsakademiens inspel i debatten och fick en central roll i IVAs seminarium till förmån för ett svenskt nanoinitiativ.

Men frågor som kan sägas beröra samhälleliga aspekter av nanoteknik fanns egentligen inte alls på agendan. Det handlade fortfarande om ett försök att konstruera nanoteknik som näringspolitiskt objekt och om att $i$ brist på industriell uppslutning trots allt förmå politiska aktörer till att skjuta till nya medel. Men det var i detta läge inte bristen på kapital som var proble- 
met. Det politiska systemet och det forsknings- och innovationspolitiska systemet blev på det hela taget handlingsförlamat när inte industrin slöt upp. Risk och vidare kontextualisering utöver konkurrenskraft var frågor som kom sent, och på liknande sätt som innovationsspåret uppträder det som en reaktion på vad som sker utanför Sverige.

Inom ramen för Kemikalieinspektionens ansvarsområde började en form av nanorisk behandlas, nämligen partiklar. Kemikalieinspektion drog i seminariet «Nanoteknikens möjligheter och risker», på IVA år 2006, slutsatsen att klassificeringssystem och nuvarande lagstiftning fungerade men behövde förbättras på sikt med avseende på testmetoder $\mathrm{m} m$. Redan ett år senare uppfattades situationen något annorlunda, $\mathrm{i}$ Kemikalieinspektionens rapport «Nanoteknik - stora risker med små partiklar?» Där beskrivs hur marknadspenetrationen av nanomaterial adderar en ökad angelägenhet till problembilden och man vill nu snabbare få ett grepp om situationen. Rapporten pekar på vikten av att ta tag i och studera de speciella problem som nya nanomaterial ger upphov till och menar att detta bör ske inom ramen för ett samlat nationellt initiativ, «En svensk strategi för nanoteknologisk utveckling, som innehåller forskning om hälso- och miljörisker» (Kemikalieinspektionen 2007: 5). Emellertid avstod aktörer från den politiska nivån att lyfta frågan om nationell samling kring nanoteknik (se nedan), det hävdades istället att det faktum att olika myndigheter nu agerar visar att systemet fungerar och att nanoteknikfrågorna är så att säga inkorporerade, och att det finns en fungerande organisering kring t ex risk. Men medan Kungliga Vetenskapsakademiens seminarium «Nanoteknikens hälso- och miljökonsekvenser» i maj 2008 och flera liknande aktiviteter har varit att sätta nanoteknikens innovations- och riskfrågor på den svenska dagordningen så uppfattar politiken det i ett betänkande som att det svenska systemet redan inkorporerat frågan om nanoteknik, och att därför inget särskilt behöver göras. Politiska aktörer avstår från att skapa samlade institutionella mekanismer kring nanoteknik, men föreslår att VINNOVA, Formas och Kemikalieinspektionen ges utökat ansvar för att bevaka hälso- och miljörisker (Betänkande 2007/08:NU8: 16-17).

I jämförelse med nivån på statens satsningar på nanovetenskap ligger risk och forskningen om samhälleliga aspekter på en olyckligt låg nivå. Dessutom saknar den forskning som faktiskt bedrivs inom dessa områden en tydlig koppling till nanoteknik som innovationsprojekt. S.k. ELSA-forskning kan i detta sammanhang ses som ett uttryck för ambitionen att balansera insatsnivåer och att skapa mer reflexiva innovationsprocesser.

\section{Den politiska arenan}

Nanoteknik och frågan om svensk nationell mobilisering förekom på den politiska arenan, men fick aldrig riktigt fotfäste. $T$ ex föreslog Vänsterpar- 
tiet att Sverige borde skapa nationella initiativ för nanoteknik (Motion 2002/03:N245 samt 2001/02:Ub372). Näringsutskottet avslog emellertid med hänvisning till att man dels först bör utröna näringslivets behov av nanoteknik, dels att regeringen redan genom Vinnova stimulerar utvecklingen inom området. Båda argumenten är intressanta. Nanoteknik är en ny formulering och existerande industrier uttrycker sällan någon åsikt $\mathrm{i}$ frågan. Den andra delen av argumentet bygger på ett missförstånd, eller bristande förståelse av det nationella systemet för innovation. Följer man FoU-medlens väg till nanoforskare är inte Vinnova vid denna tidpunkt en central aktör för nanoteknik. Några år senare, 2004, kom ny framstöt, denna gång från Kristdemokraterna om att Regeringen borde fatta beslut om att inrätta ett nationellt forskningsinstitut som skulle bli ett nordiskt centrum för nanoteknik (Motion 2004/05:N282). Även denna gång ställde sig näringsutskottet negativt (Yttrande 2004/05:NU1y).

\section{Den mediala arenan}

Någon stor debatt sker ej heller bland de opinionsledande medierna. Artiklar om nanoteknik har studerats i tre svenska stora och opinionsledande dagstidningar (Dagens Nyheter, Svenska Dagbladet och GöteborgsPosten) samt två breda och för sammanhanget viktiga tidskrifter med stort genomslag i affärs-, industri- och ingenjörskretsar (Dagens Industri samt Ny Teknik). ${ }^{2}$ Analysen har genomförts med hjälp av svenska fulltextdatabaser för tryckta medier (Mediearkivet, Presstext samt Factiva) via söktermen «nanoteknik ${ }^{\star}$ OR nanoteknologi ${ }^{*}$ » för perioden 1990 till och med 2007-08-16. Utfallet är 405 artiklar där nanoteknik nämns i text, och i praktiken är denna publicering nästan uteslutande centrerad till 2000-talet. Hela 95 procent av artiklarna under perioden är från år 2000 och framåt, med vad som kan vara en möjlig toppnotering kring år 2005. En preliminär analys av innehållet $\mathrm{i}$ materialet visar att artiklarna nästan uteslutande handlar om positiva effekter från nya eller möjliga tekniska applikationer. Endast 13 artiklar annonserar risktema direkt i titel. Trots att det är frågan om få artiklar är det tydligt att nanorisktemat lanseras kring år 2005. I maj 2008 är nanorisker t o m förstasidesstoff i Ny Teknik, där med svart rubrik «Nanolarm» rapporteras om hur kolnanorör kan ge inflammationer på liknande sätt som asbestfibrer. Under denna korta period, några få år från år 2000, introduceras nya teman, från vad nanoforskning och nanoteknik är, och via fokus mer på teknik och tillämpningar, till ett visst ökande fokus på riskfrågor.

Emellertid var det återigen frågan om en reaktion på en diskussion som fördes på annan plats. Framför allt var det rapporten från the Royal Society och Royal Academy of Engineers om nanoteknikens möjligheter och risker från 2004 som utgjorde en viktig brytpunkt för riskdiskussionen. Nanotek- 
nikens risker var tidigare ett svårhanterligt ämne eftersom det uppfattades vara spekulativt. Inte minst gällde detta frågan om radikal risk vilken främst diskuterats bland ingenjörer och futurologer. Denna rapport lyckades med att omfatta den vidare utomvetenskapliga riskdiskussionen och samtidigt skapa nytt fokus på forskning om nanopartiklar. Det kom att ske något av en stängning kring begreppet nanorisk, där idag nanopartiklar och nanotoxikologi är den klart dominerande betydelsen av nanorisk.

\section{Diskussion}

Den svenska modellen bygger på en tanke om ett gemensamt intresse att bygga samhälle och ekonomisk välfärd. I denna anda byggdes stora tekniska system och det organiserades forskning för den högteknologiska storindustrins behov och för svensk neutralitet. Dessa sammanhang var särskilt viktiga för framväxten av materialvetenskap, ur vilken nanotekniken föddes.

Men nanoteknik visar sig vara ett objekt som inte passar in i denna modell för innovation. I brist på tydliga «nano-intressen» inom industri och samhälle så har avgörande frågor om nanoteknik istället legat kvar på forskarnas och forskningsfinansiärernas bord. Resultatet är att svenska aktörer har talat lite om innovation, miljö och risker. Såtillvida att debatt funnits har den oftast initierats av vetenskapsjournalister eller enskilda forskare, och skett som respons på en diskussion vilken förts i andra länder (främst USA och England). Trots försöken att problematisera nanoteknik visar det sig att det svenska systemet agerar mer reaktivt än proaktivt.

Diskussionen och i flera fall även organiseringen av nanoteknik i ett antal länder kan ses som exempel på framväxande innovationssystem. Dessa ses som resultat av mer genomgripande aktörsmobilisering kring nanoteknik som nationellt tillväxtobjekt (vilket inte skett i Sverige). I flera fall följs denna mobilisering av mer omfattande teknikvärderingsprocesser och organisering av varaktiga processer kring studiet av nanoteknikens kontexter (vilket inte heller skett i Sverige).

Varken diskurserna kring «kunskapsekonomi» eller industrins intresse kan ge hela svaret på vilken nanoteknik vi bör satsa på. Såtillvida att den samlade analysen av nanoteknik är korrekt handlar det om en starkt generisk teknik, vilken är öppen med avseende på teknisk realisering. Därmed blir det aktiva valet av utvecklingsspår än viktigare (jfr kolnano vilken anses kunna realiseras inom vitt skilda teknikområden). Bredden i svensk nanovetenskaplig kompetens överstiger vida existerande industriella behov. Dessutom är en realisering inte avhängig existerande industri, eftersom det ändå är frågan om konstruktionen av helt nya innovationssystem. Det är också som sådant förnyelseprojekt som nanoteknik kopplas till tillväxtfrå- 
gor. En nanoforskare vilken deltagit i formandet av både det svenska och det norska nanoteknologiska FoU-systemet sammanfattar problemet väl. Vi bör ägna oss åt exempelvis nano-energi-forskning och utveckling, inte för att det är efterfrågat av de starka intressena (för det är det inte, eller har inte varit), utan för att världen behöver det (Kasemo, intervju). Universiteten är en institution i kunskapssamhället vilken kan ta större ansvar för en sådan utveckling. Den kanske viktigaste frågan kring «nano» är till vad samhället vill använda nanoforskarnas kompetens. Det behövs breda fora där aktörer av olika slag ges möjlighet att lära och diskutera om de sociala och andra system som producerar kunskap, nano-innovation, risker och välfärd. Analysen och diskussionen bör omfatta hur systemen ser ut, hur vi kan förändra dem, och i vilken riktning vill vi gå.

\section{Noter}

1 Jag vill tacka två anonyma bedömare samt redaktionen för EiP för värdefulla kommentarer till texten. Artikeln tar avstamp i forskning om nanoteknik vilken bedrivits på avdelningen för Teknik- och Vetenskapsstudier vid Göteborgs Universitet sedan 1997. Denna artikel är finansierad av Mistra, via projektet Societal aspects of nanotechnology: ecological sustainability and social robustness (NanoRobust). Projektet formulerades med det uttryckliga syftet att försöka fylla delar av ett gap i det svenska innovationssystemet för nanoteknik, vilket bestod i en avsaknad av samhällsvetenskapliga studier av den svenska nanoteknikutvecklingen. Den viktigaste inspirationen för NanoRobust är «ELSA»-programmet inom det holländska nationella nanoteknologiska inivtiativet, NanoNed, vilket initierades och leds av Arie Rip.

2 Källa för upplagor är Tidningsstatestik AB. Upplagor samt utfallet av artiklar om nano: Dagens Nyheter, 344.200 (88); Svenska Dagbladet, 197.600 (91); Göteborgsposten, 246.900, (86); Dagens Industri, 118.500 (47); Ny Teknik, 155.000 (93). Databaserna är inte fullständiga $\mathrm{m}$ a $\mathrm{p}$ artiklar skrivna av frilansjournalister.

\section{Litteratur}

Ahlgren, M. \& Franchi, H. J. (2005) Policy for a new industrial revolution - a study of nanotechnology in the USA. Swedish Institute for Growth Policy Studies ( $\mathrm{Nr}$ A2005:007).

Andersen, M. M. \& Rasmussen, B. (2006) Nanotechnology development in Denmark - environmental opportunities and risk. Rapport No R-1550(EN). Roskilde: Risø National Laboratory.

Anderson, A., Allen, S., Petersen, A. \& Wilkinson, C. (2005) The framing of nanotechnologies in the british newspaper press. Science Communication, 27 (2), s. 200-220.

Bachmann, G. (1998) Innovationsschub aus dem nanokosmos. Düsseldorff: VDITechnologiezentrum. 
Bainbridge, W. S. (2002) Public attitudes toward nanotechnology. Journal of Particle Research, 4, s. 561-570.

Barben, D., Fisher, E., Selin, C. \& Guston, D. H. (2008) Anticipatory governance of nanotechnology: Foresight, engagement and integration. I The handbook of science and technology studies, red. E. J. Hacket, O. Amsterdamska, M. Lynch \& J. Wajcman, s. 979-1000. Cambridge, MA: The MIT Press.

Beck, U. (1992) Risk society: Towards a new modernity. London: Sage.

Benner, M. \& Sandström, U. (2000) Institutionalizing the triple helix: Research funding and norms in the academic system. Research Policy, 29, s. 291-301.

Bijker, W. E. (1995) Of bicycles, bakelites, and bulbs: Toward a theory of sociotechnical change. Cambridge, MA: MIT Press.

BMBF (2004) Nanotechnology conquers markets: German innovation initiative for nanotechnology. Federal Ministry of Education and Research. Bonn och Berlin: BMBF.

Carlsson, B. (1997) On and off the beaten path: The evolution of four technological systems in Sweden. International Journal of Industrial Organization, 15, s. 775799.

Callon, M. \& Law, J. (1989) On the construction of sociotechnical networks: Content and context revisited. Knowledge and Society, 8, s. 57-83.

Cowan, R. (1990) Nuclear power reactors: A study in technological lock-in. Journal of Economic History, L (3), s. 541-567.

Defra (2007) Characterising the potential risks posed by engineered nanoparticles: A second UK government research report. London: Department for Environment, Food and Rural Affairs.

Doubleday, R. (2007) The laboratory revisited: Academic science and the responsible development of nanotechnology. NanoEthics, 1, s. 167-176.

Economic and Social Research Council (2004) The social and economic challenges of nanotechnology. Swindon, UK: Economic and Social Research Council.

Ebbesen, M. (2008) The role of the humanities and social sciences in nanotechnology research and development. Nanoethics, 2, s. 1-13.

Edqvist, O. (2003) Layered science and science policies. Minerva, 41, s. 207-221.

Felt, U. \& Wynne, B. (2007) Science and governance. Taking European knowledge society seriously. European Commission, Directorate general for Research.

Fisher, E. (2005) Lessons learned from the ethical, legal and social implications program (ELSI): Planning societal implications research for the national nanotechnology program. Technology in Society, 27, s. 321-328.

Fisher, E., Mahajan, R. L. \& Mitcham, C. (2006) Midstream modulation of technology: Governance from within. Bulletin of Science, Technology \& Society, 26, s. 485-496.

Fogelberg, H. \& Glimell, H. (2003) Bringing visibility to the invisible: Towards a social understanding of nanotechnology. STS Research Reports No 6, Avd f Teknik- och Vetenskapsstudier, Göteborgs Universitet.

Fogelberg, H. \& Sandén, B. (2008) Understanding reflexive systems of innovation: An analysis of Swedish nanotechnology discourse and organisation. Technology Analysis \& Strategic Management, 20 (1), s. 65-81.

Framtid för svensk industri (2002) Nanoteknik revolutionerar industribranscher. Nedladdad 3 september 2008 via www.framtidensindustri.se

Fridlund, M. (1999) Den gemensamma utvecklingen: Staten, storföretagen och samarbetet kring den svenska elkrafttekniken. Stockholm: Symposium. 
Granberg, A. \& Jacobsson, S. (2006) Myths or reality - a scrunity of dominant beliefs in the Swedish science policy debate. Science and Public Policy, 33 (5), s. 321-340.

Guston, D. H. \& Sarewitz, D. (2002) Real-time technology assessment. Technology in Society, 24, s. 93-109.

Hansson, S. O. (2005) Great uncertainties about small things. Techné: Research in Philosophy and Technology, 8 (2), s. 26-35.

Henrekson, M. \& Rosenberg, N. (2001) Designing efficient institutions for sciencebased entrepreneurship: Lessons from the US and Sweden. Journal of Technology Transfer, 26, s. 207-231.

Hirst, P. (1996) Making it in miniature - Nanotechnology, UK Science and its applications. London: Parliamentary Office of Science and Technology.

HM Government (2005a) Response to the Royal Society and Royal Academy of Engineering Report: 'Nanoscience and nanotechnologies: opportunities and uncertainties'. Report by HM Government in consultation with the developed administrations.

HM Government (2005b) The Governments's outline programme for public engagement on nanotechnologies. Dok nr URN/052 043. HM Government in Consultation with the Developed Administrations.

Hughes, T. P. (1986) The seamless web: Technology, science, etcetera, etcetera. Social Studies of Science, 16, s. 281-292.

Hughes, T. P. (1987) The evolution of large technological systems. I The social construction of technological systems: New directions in the sociology and history of technology, red. T. P. Hughes, W. E. Bijker \& T. Pinch, s. 51-82. Cambridge, MA: MIT Press.

Kahan, D. M., Slovic, P., Braman, D., Gastil, J. \& Cohen, G. (2006) Nanotechnology risk perceptions: The influence of affect and values. Report from the Cultural Cognition Project, Yale Law School.

Kaijser, A. (1994) I fädrens spår: Den svenska infrastrukturens historiska utveckling och framtida utmaningar. FD avhandling. Avdelningen för Teknik- och Vetenskapshistoria, Kungl. Tekniska Högskolan, Stockholm.

Kemikalieinspektionen (2007) Nanoteknik stora risker med små partiklar. Rapport nr 6/07. Sundbyberg: Kemikalieinspektionen.

Kernes, M., Macnaughten, P. \& Wilsdon, J. (2006) Governing at the nanoscale: People, policies and emerging technologies. London: Demos.

Langlais, R., Bruun, H., Hukkinen, J. \& Fogelberg, H. (2004) Anticipate the social dimensions of nanotechnology. VEST, 17 (3-4), s. 25-37.

Lash, S. (2003) Reflexivity as non-linearity. Theory, Culture \& Society, 20 (2), s. 4957.

Latour, B. (1987) Science in action. How to follow scientists and engineers through society. Cambridge, MA: Harvard University Press.

Latour, B. (1993) We have never been modern. Cambridge, MA: Harvard University Press.

Latour, B. (1996) Aramis or the love of technology. Cambridge, MA: Harvard University Press.

Lewenstein, B. V. (2005) Introduction - Nanotechnology and the public. Science Communication, 27 (2), s. 169-174.

Luhmann, N. (2005) Risk. A sociological theory. London och New Brunswick: Aldine Transactions. 
Macnaghten, P., Kearnes, M. B. \& Wynne, B. (2005) Nanotechnologies, governance, and the public deliberation: What role for the social sciences? Science Communication, 27 (2), s. 268-291.

Macoubrie, J. \& Cobb, M. D. (2004) Public perception about nanotechnology: Risks, benefits and trust. Journal of Particle Research, 6, s. 395-405.

Meyer, A. \& Persson, O. (1998) Nanotechnology - interdisciplinary patterns of collaboration and difference in application. Scientometrics, 42, s. 195-205.

Meyer, A. (2005) Nanotechnology in Sweden: Tracking patenting activity \& links between nanotech firms and swedish science. Rapport till Kungl. Ingenjörsvetenskapsakadamien. Helsingfors: Knowledge Flows.

Norges forskningsråd (2005) Nanoteknologier og nye materialer: Helse, miljø, etikk og samfunn. Oslo: Norges forskningsråd.

Norges forskningsråd (2006) Nasjonal strategi for nanovitenskap og nanoteknologi. Oslo: Norges forskningsråd.

Norges forskningsråd (2007) Nanoteknologi og nye materialer, nanovitenskap og integrasjon: Programplan 2007-2016. Oslo: Norges forskningsråd.

NUTEK (2000) Internationella jämförelser för näringslivets tillväxt. Närings- och teknikutvecklingsverket, R 2000:17. Stockholm: NUTEK.

Perez, E. \& Sandgren, P. (2007) Nanoteknikens innovationssystem. Rapport nr VA2007:01. Stockholm: VINNOVA.

Pinch, T. J. \& Bijker, W. E. (1984) The social construction of facts and artefacts: Or how the sociology of science and the sociology of technology might benefit each other. Social Studies of Science, 14, s. 399-441.

Rieke, V. \& Bachmann, G. (2004) German initiative for nanotechnology. Journal of Nanoparticle Research, 6, s. 435-446.

Rip, A. (2005) Technology assessment as part of the co-evolution of nanotechnology and society: The thrust of the TA program in NanoNed. Papper presenterat vid konferensen Nanotechnology in Science, Economy and Society, Marburg, 13-15 January, 2005.

Rothstein, B. (1992) Den korporativa staten: intresseorganisationer och statsförvaltning i svensk politik. Stockholm: Allmänna förlag.

Royal Society and Royal Academy of Engineering (2004) Nanoscience and nanotechnologies: opportunities and uncertainties. London: Royal Society and RAE.

Schot, J. \& Rip, A. (1997) The past and future of constructive technology assessment. Technology Forecasting \& Social Change, 54 (2-3), s. 251-268.

Schummer, J. (2007) Identifying ethical issues of nanotechnologies. I Nanotechnology: Science, ethics and politics, red. H. ten Have, s. 79-98. Paris: UNESCO Publishing.

Smith, M. R. \& Reber, S. C. (1989) Contextual contrasts: Recent trends in the history of technology. I In context: History and the history of technology, red. S. H. Cutcliffe \& R. C. Post, s. 133-149. Bethlehem: Leigh University Press.

Staudenmaier, J. M. (1985) Technology's storytellers. Cambridge, MA: MIT Press.

Stephens, L. F. (2005) News narratives about nano S\&T in major U.S. and non-U.S newspapers. Science Communication, 27 (2), s. 175-199.

Sörlin, S. (red.) (2005) I den absoluta frontlinjen. En bok om forskningsstiftelserna, konkurrenskraften och politikens möjligheter. Nora: Bokförlaget Nya Doxa.

Tekes (2000) Nanotechnology research programme 1997-1999. Rapport nr 11/2000. Helsingfors: National Technology Agency. 
Tekes (2005) Forskningsprogrammet för nanovetenskap (FinNano) 2006-2010. Helsingfors: Finlands Akademi.

Teknisk Framsyn (2000a) Det framsynta samhället. Nedladdad 1 juli 2008 via www.tekniskframsyn.nu

Teknisk Framsyn (2000b) Panel 4: Produktionssystem. Nedladdad 1 juli 2008 via www.tekniskframsyn.nu

Teknisk Framsyn (2000c) Panel 5: Informations- och kommunikationssystem. Nedladdad 1 juli 2008 via www.tekniskframsyn.nu

Teknisk Framsyn (2000d) Panel 6: Material och materialflöden $i$ samhället. Nedladdad 1 juli 2008 via www.tekniskframsyn.nu

Teknisk Framsyn (2004a) Vägval för Sverige! Nedladdad 1 juli 2008 via www.tekniskframsyn.nu

Teknisk Framsyn (2004b) Produktionssystemet Sveriges välfärdsmotor. Nedladdad 1 juli 2008 via www.tekniskframsyn.nu

Teknisk Framsyn (2004c) Nytt, bättre och säkrare IT i framtidssamhällets tjänst. Nedladdad 1 juli 2008 via www.tekniskframsyn.nu

Teknisk Framsyn (2004d) Material och materialflöden Utmaningar och möjligheter. Nedladdad 1 juli 2008 via www.tekniskframsyn.nu

UK Trade \& Investment (2008) Nanotechnology in the UK. Informationsbroschyr från UK Trade \& Investment.

UK Advisory Group on Nanotechnology Aplications (2002) New dimensions for manufacturing: A UK strategy for nanotechnology. Rapport till Ministry for Science and Innovation.

Van Merkerk, R. O. \& Van Lente, H. (2005) Tracing emerging irreversibilities in emerginng technologies: The case of nanotubes. Technology Forecasting \& Social Change, 72, s. 1094-1111.

Videnskabsministeriet (2004) Teknologisk fremsyn om dansk nanovidenskap og nanoteknologi. Handlingsplan. Köpenhamn: Ministeriet for Videnskab, Teknologi og Udvikling.

Weinberger, H. (1996) Nätverksentreprenören: En historia om teknisk forskning och industriellt utvecklingsarbete från den Malmska utredningen till Styrelsen för teknisk utveckling. FD avhandling, Avdelningen för Teknik- och Vetenskapshistoria, Kungl. Tekniska Högskolan, Stockholm.

Öberg, P-O. (1997) Medborgarnas inflytande och särintressenas makt: korporatism och lobbying $i$ statsförvaltningen. Rapport till förvaltningspolitiska kommissionen. Statsvetenskapliga Institutionen, Uppsala Universitet.

Riksdagstryck (via www.riksdagen.se):

- Motion 2001/02:Ub372 «Nanoteknik»

- Motion 2002/03:N245 «Nanoteknik»

- Motion 2004/05:N282 «Nanoteknik för Sveriges framtid»

- Yttrande 2004/05:NU1y «Forskning»

- Betänkande 2007/08:NU8 «Vissa näringspolitiska frågor»

Intervju:

Kasemo, Bengt: Professor i Fysik, Chalmers Tekniska Högskola, Transkriberad intervju från 2005-12-13. Beskrivningen i text är ej ordagrant citat utan är en sammanfattning av ett kortare stycke ur transkriberad intervju. 